\section{Commentary: Preventing postoperative surgical-site infections in cardiac surgery: Just follow the guidelines}

\author{
Harold L. Lazar, MD
}

In this edition of JTCVS online, Takami and colleagues ${ }^{1}$ report the impact of preoperative nasopharyngeal cultures (NCx) on surgical-site infections (SSIs) after cardiac surgery. In their study, a positive preoperative NC was an independent risk factor for a postoperative SSI. However, the pathogen isolated in preoperative $\mathrm{NCx}$ was infrequently isolated from postoperative SSIs. The authors concluded that in addition to screening for methicillin-resistant Staphylococcus aureus, preoperative NCx may be useful to predict SSI following cardiac surgery performed via a sternotomy.

Unfortunately, there are numerous issues with this study that limit the conclusions that can be made. The most serious flaw was the failure of the authors to follow the recommendations of the Society of Thoracic Surgeons (STS) guidelines on the use of perioperative antibiotics ${ }^{2,3}$ and the American Association for Thoracic Surgery (AATS) guidelines for the prevention and treatment of sternal wound infections. ${ }^{4}$ Adherence to these guidelines has resulted in an incidence of deep sternal wound infections (DSWIs) of $0.3 \%$ to $0.5 \%$ in the STS database. ${ }^{5}$ The incidence of chest wound SSI in this current study was $1.7 \%$, nearly 3 to 4 times greater! Other areas of nonadherence to the STS and AATS guidelines in this study included the following:

1. Mupirocin ointment was used for only 3 days instead of the recommended 5-day course.

\footnotetext{
From the Division of Cardiac Surgery, The Boston University School of Medicine, Boston, Mass.

Disclosures: The author reported no conflicts of interest.

The Journal policy requires editors and reviewers to disclose conflicts of interest and to decline handling or reviewing manuscripts for which they may have a conflict of interest. The editors and reviewers of this article have no conflicts of interest.

Received for publication Sept 14, 2021; revisions received Sept 14, 2021; accepted for publication Sept 24, 2021; available ahead of print Nov 5, 2021.

Address for reprints: Harold L. Lazar, MD, 80 E. Concord St, Boston, MA 02118 (E-mail: harold.1.lazar@gmail.com).

JTCVS Open 2021;8:489-90

2666-2736

Copyright (C) 2021 The Author(s). Published by Elsevier Inc. on behalf of The American Association for Thoracic Surgery. This is an open access article under the CC BY-NC-ND license (http://creativecommons.org/licenses/by-nc-nd/4.0/).

https://doi.org/10.1016/j.xjon.2021.09.049
}

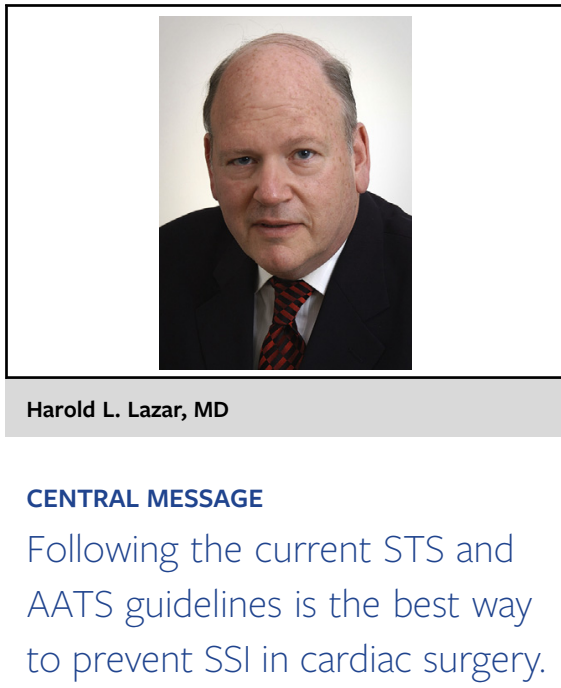

2. Patients did not receive additional antibiotic coverage for gram (-) organisms when only vancomycin was used as the sole perioperative antibiotic. It is the recommendation of both the STS and AATS guidelines that an aminoglycoside be added for one preoperative and postoperative dose when vancomycin is used as the primary prophylactic antibiotic to achieve optimal gram (-) coverage. ${ }^{2-4}$ This may explain the isolation of Enterococcus and Pseudomonas species that were seen in both the pharyngeal and chest SSI cultures in patients with a DSWI. Furthermore, when enterococcus and pseudomonas species were isolated preoperatively, no attempt was made to broaden the perioperative coverage against these pathogens, and more importantly, to identify whether they were associated with infections in other sites, specifically the pulmonary and genitourinary systems.

3. The authors removed bone wax before closing the sternum to decrease the risk of infection. However, it is unclear as to how you can remove all the bone wax without causing bleeding from the sternal edges once it has been applied. Bone wax should be avoided in all sternotomies, which is a Class III recommendation in the AATS guidelines. ${ }^{4}$ Vancomycin paste has been shown to eliminate DSWI, ${ }^{6}$ and its use in all sternotomy patients is now a Class I recommendation in the AATS guidelines. ${ }^{4}$ It is also hemostatic.

The incidence of the use of postoperative tracheostomies in this study was $8.3 \%$, which is greater than at most centers, and was identified as a risk factor for SSI. The authors plan to limit their use of all types of tracheostomies in their practice. In view of their results, the "liberal" use of 
tracheostomies cannot be considered a "best practice" for postop cardiac surgery patients.

In view of these limitations, what can we conclude from this study? A positive NCx for organisms other than staphylococcal species should prompt a thorough search for other sites of infections in patients undergoing cardiac surgery and the institution of a broader spectrum of antibiotics to treat these organisms. The STS and AATS guidelines were instituted to eliminate postoperative cardiac surgical SSIs. The study by Takami and colleagues ${ }^{1}$ reminds us what happens when these guidelines are not followed.

\section{References}

1. Takami Y, Amano K, Sakurai Y, Akita K, Hayashi R, Maekawa A, et al. Impact of perioperative nasopharyngeal cultures on surgical site infection after open heart surgery. J Thorac Cardiovasc Surg Open. 2021;8:478-87.

2. Edwards FH, Engelman RM, Houck P, Shahian DM, Bridges CR. The Society of Thoracic Surgeons practice guidelines series: antibiotic prophylaxis in cardiac surgery. Part I: duration. Ann Thorac Surg. 2006;81:397-404.

3. Engelman R, Shahian D, Shemin R, Guy TS, Bratzler D, Edwards F, et al. The Society of Thoracic Surgeons practice guideline series: antibiotic prophylaxis in cardiac surgery. Part II: antibiotic choice. Ann Thorac Surg. 2007;83: 1569-77.

4. Lazar HL, VanderSalm T, Engelman R, Orgill D, Gordon S. Prevention and management of sternal wound infections. J Thorac Cardiovasc Surg. 2016;152: 962-72.

5. D'Agostino RS, Jacobs JP, Bardhwar V, Fernandez FG, Paone G, Wormuth DW. The Society of Thoracic Surgeons Adult Cardiac Surgery database: 2018 update on outcomes and quality. Ann Thorac Surg. 2018;105:15-23.

6. Lazar HL, Ketchedjian A, Haime M, Karlson K, Cabrol H. Topical vancomycin in combination with perioperative antibiotics and tight glycemic control helps to eliminate sternal wound infections. J Thorac Cardiovasc Surg. 2014;148: 1035-40. 